Revista de Economia Política, vol. 29, no 2 (114), pp. 302-318, abril-junho/2009

\title{
Torricelli, energia a vapor e o sentido tecnológico da Revolução Científica
}

CARLOS EDUARDO SUPRINYAK*

Torricelli, steam power, and the technological drift of the Scientific Revolution. Starting from Evangelista Torricelli's pneumatic discoveries, we try to show that the crucial discoveries in pure science associated with the Scientific Revolution, although they may not have found immediate practical applications, have markedly impelled technological progress in the medium term - contrary to the diffused notion which states that the links between science and technology during the modern period have been tenuous, at best. Torricelli's ideas have turned into one of the privileged research areas for then newborn experimental program, actively participating in a process of reformulation in scientific research's epistemological base, which have culminated in steam power productive application.

Keywords: Torricelli; steam power; Scientific Revolution; technology.

JEL Classification: N73; O31.

\section{INTRODUÇÃO}

Em seu clássico artigo How exogenous is science?, Nathan Rosenberg busca ressaltar a relevância de questões econômicas e tecnológicas na determinação dos rumos do progresso científico. Para ilustrar a validade histórica de seu argumento, Rosenberg recorre aos experimentos realizados no século XVII pelo cientista italiano Evangelista Torricelli na tentativa de mensurar a pressão atmosférica:

[T] he influence of certain technological concerns on the growth of scientific knowledge has long been recognized. Torricelli's demonstration of the weight of air in the atmosphere, a scientific breakthrough of

\footnotetext{
* Doutorando em Economia pelo Centro de Desenvolvimento e Planejamento Regional da Universidade Federal de Minas Gerais - CEDEPLAR/UFMG. E-mail: suprinyak@cedeplar.ufmg.br. Submetido: Março 2007; Aprovado: Agosto 2007.
} 
fundamental importance, was an outgrowth of his attempt to design an improved pump (Rosenberg, 1982: 142).

Para Rosenberg, as descobertas de Torricelli no campo da pneumática configuram um caso típico de avanço científico originado na resolução de problemas de ordem tecnológica. Curiosamente, Joel Mokyr, outro grande especialista em história da tecnologia, também utilizou a figura de Torricelli como exemplo contundente da força da causalidade em sentido oposto. Para Mokyr, é a seminal descoberta da existência de uma pressão atmosférica que está na raiz do desenvolvimento da máquina atmosférica de Savery e da máquina a vapor de Newcomen e, posteriormente, Watt:

The basic idea for the construction of an atmospheric engine is based on the realization that an atmosphere exists. What seems today a commonplace insight was the fruit of the work of Evangelista Torricelli [...] and Otto von Guericke [...]. It occurred to many who had grasped the newly discovered phenomenon that if a vacuum could be created repeatedly, the force of atmospheric pressure could yield a novel source of power (Mokyr, 1990: 84).

$[S]$ team power would have been unimaginable without the insights of Torricelli and Guericke into atmospheric pressure (Mokyr, 1990: 168).

Entretanto, o próprio Mokyr, alhures, presta testemunho tácito quanto à obscuridade deste processo de transferência do conhecimento científico para o domínio das aplicações tecnológicas. Para ele, os mecanismos de transposição entre a ciência dos filósofos naturais e a tecnologia dos artesãos e engenheiros prototípicos não são nada claros:

[T] he steam engine depended on the understanding of atmospheric pressure, discovered by continental scientists such as Evangelista Torricelli and Otto von Guericke, which somehow must have filtered down to Newcomen despite the fact that his world was the local blacksmith's rather than the cosmopolitan academic scientist's (Mokyr, 1993: 79).

Partindo da instigante evidência histórica sobre a atividade científica de Torricelli e seus desdobramentos, o objetivo do presente artigo é apresentar um estudo de caso acerca das interconexões entre ciência e tecnologia durante o período da Revolução Científica - mais precisamente, durante a segunda metade do século XVII e primeiras décadas do século XVIII. Ao longo da exposição, buscarei traçar a trajetória evolutiva dos avanços científicos associados às descobertas de Torricelli, culminando no desenvolvimento da máquina a vapor. Ao mesmo tempo, veremos a consolidação, quase um século antes da eclosão da Revolução Industrial, de uma nova perspectiva epistemológica perante a natureza, uma forma me- 
canicista de pensar que foi condição prévia das grandes inovações tecnológicas da segunda metade do século XVIII.

\section{TORRICELLI E A CIÊNCIA TECNOLÓGICA}

Evangelista Torricelli, cientista italiano nascido em Faenza em 1608, foi um dos mais destacados discípulos de Galileu no século XVII. Embora apenas tenha mantido contato pessoal com Galileu durante os últimos meses de vida deste, conhecia as obras do mestre desde a juventude, por meio da influência de seu tutor, Benedetto Castelli. Após a morte de Galileu, Torricelli foi apontado para sucedêlo como matemático da corte de Ferdinando II e professor de matemática na Universidade de Pisa. Nesta função, preservou e aprimorou o legado de Galileu, trabalhando em diversas áreas da matemática e geometria puras, além de pesquisas aplicadas relacionadas à astronomia, pneumática e mecânica dos sólidos e fluidos. Juntamente com Viviani, foi um dos idealizadores da Accademia del Cimento, uma academia científica com um viés mecanicista e experimental, precursora das sociedades científicas que se disseminariam por toda a Europa durante a segunda metade do século XVII (Wolf, 1962: 55-59, 222-223).

Como discípulo de Galileu, Torricelli herdou seus problemas teóricos. De todos eles, o que mais nos interessa aqui diz respeito às propriedades da atmosfera $\mathrm{e}$ à possibilidade de existência do vácuo. Galileu havia sido atraído para esta discussão por meio de um problema prático: ao observar algumas bombas de sucção de água em operação nas minas da Toscana, notou que, após a coluna de água atingir a altura-limite de 32 pés, as bombas não eram mais capazes de erguê-la. À época, a explicação teórica para o funcionamento de bombas de sucção estava relacionada à doutrina escolástica do horror vacui, segundo a qual a natureza tem aversão ao vácuo e, portanto, impele os corpos a ocupar todos os espaços. Galileu então percebeu: se as bombas de sucção apenas funcionam até uma altura-limite, havia algo de errado com a doutrina do horror vacui. Não obstante, não foi capaz ele próprio de propor uma solução alternativa satisfatória para o problema, postulando apenas que, após atingir a altura de 32 pés, a coluna de água se quebraria sob seu próprio peso (Cardwell, 1972: 51-52; Usher, 1993: 441; Wolf, 1962: 92).

Torricelli foi o responsável pela solução do enigma. Substituindo a água pelo mercúrio, um líquido substancialmente mais denso e pesado, Torricelli imaginava que seria capaz de reproduzir o fenômeno das bombas d'água em proporções menores, mais adequadas à pesquisa experimental. Idealizou um experimento em que um tubo de vidro cheio de mercúrio, fechado em uma das extremidades e aberto na outra, seria mantido em posição vertical com sua extremidade aberta submersa em um recipiente também cheio de mercúrio. Com esta emulação do mecanismo de uma bomba de sucção, pretendia verificar qual o poder de atração exercido pelo vácuo sobre o mercúrio. Após permitir o contato do mercúrio no tubo com aquele do recipiente, Torricelli constatou que a coluna de mercúrio no tubo descia 
para uma altura de aproximadamente trinta polegadas, onde então se mantinha constante, deixando um espaço vazio no segmento de tubo acima.

$\mathrm{O}$ resultado assim alcançado teve consequências marcantes. Em primeiro lugar, forneceu evidências experimentais acerca da possibilidade de existência do vácuo, contrariando a doutrina do horror vacui - o espaço vazio no tubo passou a ser conhecido como "vácuo torricelliano". Além disso, a hipótese elaborada por Torricelli para explicar o fenômeno revolucionaria para sempre a pneumática: em oposição à ideia de que era o vácuo que atraía os fluidos, afirmou que era o peso da atmosfera - a pressão atmosférica - que, ao atuar sobre o mercúrio em repouso no recipiente, porém não sobre o mercúrio dentro do tubo (onde não havia ar), exercia a força necessária para elevar a coluna até uma determinada altura; o limite seria no ponto em que o peso da coluna de mercúrio dentro do tubo fosse equivalente ao peso do ar sobre o mercúrio no recipiente. Finalmente, ao constatar variações na altura da coluna de mercúrio em situações experimentais diversas, Torricelli também vislumbrou a possibilidade de mudanças na pressão atmosférica; desta forma, sua experiência também constitui a invenção do princípio do barômetro (Cardwell, 1972: 51-52; Hall, 1967: 123; Shapin \& Schaffer, 1985: 41; Wolf, 1962: 92-93).

Assim, percebemos que a escolha de Rosenberg é plenamente justificada. $\mathrm{O}$ experimento crucial de Torricelli e a descoberta do princípio da pressão atmosférica constituem avanços científicos fundamentais que tiveram sua origem na observação de problemas eminentemente práticos, tecnológicos. Em uma época de expansão acelerada das atividades mineradoras, a drenagem das minas era uma necessidade premente. Este problema cativou a sensibilidade de Galileu; também à sua superação foram consagrados os esforços de Savery e Newcomen mais de meio século depois, conforme veremos adiante.

No entanto, seria impreciso - ou mesmo incorreto - atribuir esta apreensão da potencialidade científica de um problema tecnológico meramente à perspicácia da mente de Galileu. Durante a primeira metade do século XVII, as bases epistemológicas da filosofia natural estavam sendo discutidas e questionadas a partir de uma grande variedade de perspectivas, boa parte delas estreitamente relacionada com uma maior ênfase nos processos empíricos, na observação e na experimentação, como base para o conhecimento da natureza (Jacob, 1988: 10-69). O foco desta pioneira corrente empirista estava localizado, é claro, na Inglaterra; seu principal porta-voz chamava-se Francis Bacon.

Embora goze de prestígio variado nos diversos círculos historiográficos, o nome de Bacon é frequentemente associado com o surgimento da moderna concepção de ciência. Sua ênfase sobre a observação imparcial da natureza, coleta e catalogação da maior quantidade possível de evidências empíricas, importância de vastas e abrangentes histórias naturais como base sólida para construção do edifício da filosofia natural - todas estas exortações metodológicas soam familiares aos ouvidos modernos, em contraste com a estranheza causada pelas especulações metafísicas típicas do pensamento escolástico, que visavam combater. Em muitos aspectos, é possível afirmar que o cânone baconiano constitui até hoje o ideal me- 
todológico daqueles praticantes das ciências naturais - ou mesmo sociais - menos instruídos no campo da epistemologia.

Mas não é apenas a ênfase na observação que caracteriza a proposta metodológica baconiana. Em estreita correlação com este princípio norteador, Bacon também dedicou seus esforços à promoção de uma ciência mais pragmática, mais instrumental. Para Bacon, a ciência deveria ser útil; deveria ajudar a aprimorar as condições materiais do homem. Mokyr, ao descrever o contexto cultural do século XVIII, o século da Revolução Industrial, ressalta a difusão do ideário baconiano:

Above all was the increasingly pervasive belief in the Baconian notion that we can attain material progress (that is, economic growth) through controlling nature, and that we can only harness nature by understanding her in order, as he himself put it, to bring about "the relief of man's estate" (Mokyr, 2005: 291).

A revolução epistemológica proposta por Bacon pretendia primeiramente compreender a natureza, via observação, para então dominá-la, visando aprimorar a condição humana, promover o bem-estar da humanidade. Mais do que isto, Bacon acreditava que a ciência poderia se converter em um instrumento político: se institucionalizada na esfera pública, a produção do conhecimento poderia ser gerida pelo Estado e utilizada da forma mais proveitosa para seus desígnios maiores (Jacob, 1988: 31-33). Como ressalta Cardwell, Bacon desempenhou papel fundamental na constituição de um ambiente sociopolítico favorável ao desenvolvimento científico:

[P]erhaps Bacon's real importance was that he was the first man to lay down a social and political programme for science and technology. He was, in fact, a sociologist of science and technology (Cardwell, 1972: 30).

If Galileo provided the correct, and therefore fruitful, insights at least in so far as the mechanical sciences and technology are concerned, Bacon described the social framework within which these ideas could be made increasingly effective (Idem: 36).

Assim, constatamos que a primeira metade do século XVII testemunhou o surgimento de perspectivas radicalmente novas quanto à natureza e aos objetivos próprios do conhecimento científico. O legado destes pioneiros viria a ser disseminado, e finalmente institucionalizado, durante a segunda metade do século. As pontes unindo ciência e tecnologia eram construídas.

\section{COSMOPOLITISMO E INSTITUCIONALIZAÇÃO}

Após a morte de Torricelli, suas explorações no campo da pneumática seguiram fazendo parte do programa experimental da Accademia del Cimento, em es- 
pecial por obra de Viviani. Entretanto, a repercussão maior de suas descobertas ocorreu fora dos domínios italianos - mais especificamente, na França.

Vimos de passagem, na primeira seção, que a formulação original do princípio da pressão atmosférica não se deve exclusivamente a Torricelli. Simultaneamente, o cientista alemão Otto von Guericke realizava seus próprios experimentos pneumáticos, o mais célebre entre eles conhecido como os hemisférios de Magdeburgo. Prefeito da cidade de Magdeburgo durante o período 1646-1676, Guericke pôde realizar este experimento público de alto efeito dramático. Posto de forma simples, consistia em unir dois hemisférios ocos de cobre e então sugar o ar de dentro do recipiente fechado - Guericke é também creditado como inventor da primeira versão rudimentar de uma bomba de ar. Após exaurir todo o ar de dentro de sua bola de cobre, um grupo de oito cavalos era então preso a cada hemisfério, pressionando em sentidos contrários. Constatou que os dezesseis cavalos não eram capazes de separar os hemisférios. Entretanto, uma vez que o ar era novamente inserido no recipiente, os hemisférios eram facilmente separáveis. Desta forma, por meio de um experimento diverso, Guericke também demonstrou a existência da pressão atmosférica e refutou a doutrina do horror vacui (Cardwell, 1972: 54-56; Usher, 1993: 442-443).

Quase simultaneamente, na Itália e na Alemanha, o conhecimento no campo da pneumática avançava drasticamente por meio da descoberta do princípio fundamental da pressão atmosférica. Não obstante, foi na França que estes experimentos cruciais foram realizados em sua forma definitiva, em especial pelas mãos de Pascal. Em 1644, um ano após Torricelli ter realizado suas experiências com o tubo de mercúrio, seus resultados chegaram a Paris, até as mãos do filósofo Marin Mersenne. Pascal tomou então conhecimento das pesquisas de seu colega italiano e decidiu reproduzi-las por conta própria. Ao longo do restante da década, dedicou-se a repetir o experimento de Torricelli em suas mais diversas variantes, especialmente sua reprodução a diversas altitudes. Seus resultados foram detalhadamente registrados e organizados, sendo publicados no início da década de 1660, logo após a morte de Pascal. Alcançando grande divulgação, as obras de Pascal consolidaram-se como a forma definitiva das experiências com o tubo de Torricelli e com a mensuração da pressão atmosférica (Usher, 1993: 443-444).

Desta forma, podemos perceber que os avanços científicos no campo específico da pneumática, durante o século XVII, estavam longe de ser fatos isolados ou fruto de genialidade individual. Pelo contrário, as pesquisas na área estavam sendo conduzidas simultaneamente, com notável sucesso, em locais distintos - Itália, França, Alemanha - e atestam o avanço do processo de internacionalização do conhecimento científico nesse período. Para Mokyr, esta tendência cosmopolita, então iniciada, constitui uma das características marcantes da cultura científica do século XVIII:

In the eighteenth century access costs fell in part because national and geographic barriers were easily crossed. The Enlightenment movement as a whole was cosmopolitan, with the typical scientist or philoso- 
pher more a citizen of the Republic of Letters than of his own country (Mokyr, 2005: 305).

Rather than a set of competing players or a horse race, we should regard the European Enlightenment as a joint project in which collective knowledge was produced, increasingly accessible to participants (Idem: 314).

Uma série de mudanças ocorridas durante o século XVII contribuiu para esta internacionalização e maior disseminação dos avanços científicos. De extrema importância, sem dúvida, foi o desenvolvimento da imprensa e a multiplicação dos meios impressos de comunicação. Tanto no que se refere à ciência pura quanto aos padrões tecnológicos, a imprensa viabilizou uma divulgação mais precisa e abrangente dos avanços alcançados:

A possibilidade de produzir livros a custos baixos e em padrões mais altos de precisão contribuiu decisivamente para a difusão do conhecimento científico e técnico, intensificando assim os efeitos das novas atividades intelectuais e contribuindo com um elemento essencial para o desenvolvimento do conhecimento moderno, com sua ênfase crescente na comunicação e na instrução escrita, de uma forma distinta da oral (Usher, 1993: 317).

The large number of "how-to" books published after 1450 provided a vehicle through which technology was diffused through Europe. [...] Thus, a technical literature emerged, written by engineers for engineers, and technical knowledge became increasingly communicable and thus cumulative (Mokyr, 1990: 64-65)

Podemos relacionar uma série de outros fatores que também contribuíram com a disseminação do conhecimento científico pela Europa: aumento generalizado nas taxas de alfabetização da população europeia; aumento no número de bibliotecas disponíveis, especialmente nas nascentes sociedades científicas; erosão do status do latim como língua oficial, e consequente disseminação das línguas vernáculas em sua forma escrita. A respeito deste último ponto, Margaret Jacob associa o uso mais amplo das línguas vernáculas ao desejo dos autores da "nova ciência" de atingir um público específico, composto pelas cortes e emergentes elites urbanas:

Quite purposefully the followers of Copernicus, in particular Galileo, wrote in Italian (or simply in the vernacular), and in so doing, they appealed not only to the clergy but, more dramatically, to the educated laity in the urban commercial centers as well as to the new monarchs and the salons of the princes and aristocrats. At every turn these vernacular appeals sought to integrate science into the values and interests of the elites to whom they primarily spoke (Jacob, 1988: 12). 
Para Jacob, Galileu é uma peça fundamental neste processo de aproximação entre as elites e a comunidade científica. Ao defender o ideal baconiano do conhecimento útil, Galileu criou um apelo que foi acolhido pelas novas elites, que passaram a ver a ciência como uma fonte potencial de aprimoramento de suas condições materiais. As tensões entre Galileu e as autoridades eclesiásticas romanas, em um período de crescente fragmentação da unidade religiosa europeia, aguçou ainda mais o interesse de indivíduos educados em todas as partes do mundo. Por fim, o efeito dramático da condenação final de Galileu construiu uma ponte entre o conhecimento científico e uma atitude religiosa anti-romana, que encontrou terreno fértil nos países de orientação protestante - em especial, a Inglaterra (Jacob, 1988: 16-25).

Em seu clássico trabalho sobre o tema, Robert Merton defende a tese de que o puritanismo foi uma influência decisiva na promulgação dos ideais científicos no período moderno. Ao forjar compatibilidade entre razão e fé, associada a uma postura francamente empirista, a teologia puritana possibilita a valorização da ciência em duas frentes: por um lado, como forma de compreender e glorificar a obra divina; por outro, promovendo o aprimoramento das condições materiais da sociedade, resultado visto a partir da perspectiva puritana como afim aos desígnios divinos (Merton, 1984: 95-102). Nas palavras do autor:

[O] estudo dos fenômenos naturais é um meio efetivo de colocar em relevo a glória de Deus. [...] Desta maneira direta, a religião deu sua sanção à ciência e elevou a estima social dos que efetuavam investigações científicas, com a intensificação e difusão associadas do interesse por tais realizações (Merton, 1984: 100-101).

Durante grande parte do período moderno, as universidades não desempenhavam o papel de fomentadoras do desenvolvimento científico que hoje a elas associamos. Pelo contrário, as universidades eram redutos da filosofia escolástica que resistiam ao declínio dos valores medievais; desta forma, possuíam um pendor para a exploração de questões metafísicas, não dedicando atenção para as variantes empíricas e experimentais vinculadas ao programa baconiano. Em resposta a sua preterição nas instituições tradicionais do conhecimento, os seguidores de Bacon optaram por criar seu próprio ambiente institucional. Foi assim que, originando-se nas reuniões intelectuais realizadas em clubes e cafés, surgiram as sociedades cultas (learned societies).

O fenômeno das sociedades cultas é de fundamental importância para compreendermos esta gradual aproximação entre filosofia natural e tecnologia, pois ali se juntaram indivíduos das mais diversas classes sociais e orientações filosóficas, unidos na crença de que a ciência poderia - e deveria - ser orientada para o aprimoramento das condições materiais da sociedade. A Accademia del Cimento, como vimos, foi uma precursora das sociedade cultas. Na França, a Académie des Sciences foi fundada em 1666 num esforço conjunto de Colbert e do cientista holandês Christiaan Huygens - sob os auspícios da monarquia de Luís XIV - visando ao desenvolvimento das artes e ofícios, em especial aquelas vinculadas a propósitos 
militares (Jacob, 1988: 63). Não obstante, a mais célebre e significativa de todas as sociedades cultas constituídas no período foi, sem dúvida, a Royal Society.

Fundada em 1662, logo após a Restauração, a Royal Society de Londres assumiu explicitamente sua orientação baconiana. Dentre os objetivos da Sociedade, destacava-se a intenção de compilar vastas histórias naturais e de ofícios (Wolf, 1962: 61). Dentro do panorama que buscamos traçar neste trabalho, a Royal Society é importante por uma série de razões: mais do que em qualquer outra sociedade, ali foram disseminados os princípios do programa experimental de pesquisa; a Sociedade também se transformou num símbolo da união entre a ciência e as elites - ser membro da Royal Society era um privilégio que conferia enorme prestígio social; por fim, foram seus membros que se incumbiram de dar continuidade ao legado de Torricelli, Guericke e Pascal no campo da pneumática.

A perspectiva adotada pela Royal Society perante a produção do conhecimento enfatizava a importância do experimento como forma de resolução de controvérsias e estabelecimento definitivo de resultados. Embora hoje esta pareça uma proposição trivial, tal não era o caso no ambiente sociocultural do século XVII. Os defensores do "programa experimental" precisaram travar uma árdua batalha contra filosofias de orientação mecanicista, porém não experimentalmente orientadas. Embora os contendores de ambos os lados estivessem de acordo em seu repúdio à filosofia escolástica, suas perspectivas epistemológicas eram irreconciliáveis. Os proponentes do mecanicismo racionalista - que tinham em Hobbes seu representante na arena pública - não reconheciam a legitimidade do experimento científico no processo de descoberta e consolidação do conhecimento (Shapin \& Schaffer, 1985).

Embora o programa experimental tenha saído vitorioso no longo prazo, a batalha ainda era intensa nas primeiras décadas de existência da Royal Society. Por meio da atuação de Robert Hooke e Robert Boyle, a Sociedade defendeu vigorosamente a fundamentação da ciência sobre bases experimentais, enfatizando a publicidade e a replicabilidade do conhecimento assim produzido. Em consequência da primazia atribuída ao conhecimento experimental, a Sociedade forjou a aproximação entre filósofos e artesãos, cientistas e técnicos. Para realizar experimentos, não era suficiente dominar teoricamente o problema; era necessário dominar as técnicas que poderiam convertê-lo em uma proposição experimentalmente demonstrável. Filósofos naturais e fabricantes de instrumentos passaram a cooperar estreitamente, exercendo influência recíproca na evolução de ambas as especialidades. Enquanto a ciência usufruía das possibilidades oferecidas pelo estado da técnica, a tecnologia dos instrumentos seguia as demandas do programa científico (Hall, 1967: 119, 129-130; Merton, 1984: 176).

A parceria entre Hooke e Boyle talvez seja o exemplo mais contundente desta aproximação entre o filósofo e o técnico. Hooke ocupava o cargo de "curador de experimentos" da Royal Society - a própria existência de tal cargo evidencia de forma clara a orientação metodológica da Sociedade. No desempenho de suas funções, Hooke era encarregado de idealizar e operacionalizar experimentos para os encontros semanais da sociedade. Foi Hooke o responsável pela construção das diversas bombas de ar que Boyle utilizou em seus célebres experimentos pneumáti- 
cos - alegadamente, Hooke era o único na Inglaterra de então capaz de colocar a bomba de ar em funcionamento. Desta forma, a seminal série de experimentos com a bomba de ar caracteriza-se como uma obra conjunta entre Boyle e Hooke. A importância deste último na parceria é destacada de forma correta por Bennett:

He [Hooke] was a link between the natural philosophers and the instrument makers - perhaps really at home with neither the one nor the other. The Society, and Hooke in particular, emphasized the importance of such a liaison but only he really carried it on (Bennett, 1980: 34).

Os experimentos de Boyle com a bomba de ar agregaram instâncias confirmatórias aos princípios pneumáticos formulados nas décadas anteriores. Uma das demonstrações mais utilizadas por Boyle consistia na reprodução da experiência de Torricelli com o tubo de mercúrio dentro do recipiente exaurido de ar - confirmando que era a pressão do ar, e não a aversão da natureza ao vácuo, que ocasionava a elevação da coluna de mercúrio. Este aparente poder do experimento crucial para resolver definitivamente controvérsias científicas foi um dos principais baluartes da defesa do programa experimental:

[T] he Torricellian experiment was intimately associated with the claim of experiment to settle belief about nature, to end controversy, and to generate consensus (Shapin \& Schaffer, 1985: 42).

Em linha com a hipótese de Merton, a Royal Society era uma instituição impregnada de valores puritanos. Suas sementes se encontravam no chamado Círculo de Hartlib, composto de indivíduos reformistas alinhados aos interesses do Parlamento. Embora formalmente instituída no ambiente conciliatório dos primeiros anos da Restauração, a Sociedade nunca perdeu sua inclinação puritana. Vários de seus membros mais ilustres no período, como Boyle e Newton, eram adeptos da doutrina. Desta forma, os laços entre ciência e progresso material foram ainda mais reforçados no seio da Sociedade (Jacob, 1988: 73-75; Merton, 1984: 173181). Há um vínculo estreito entre a preferência pelo conhecimento experimentalmente demonstrável e o desejo de utilizar o conhecimento assim adquirido para o bem-estar da humanidade. De modo bastante ilustrativo, Hooke assim qualifica o estudo das propriedades do ar: "highly usefull and absolutely necessary to the well being of the mankind". ${ }^{1}$

O novo programa metodológico proposto pelas sociedades cultas, em especial a Royal Society, incorporou as frentes de pesquisa abertas pelos filósofos empiricamente orientados da primeira metade do século, promovendo, neste processo, a aproximação entre a ciência e os anseios da sociedade. Tanto o ponto de partida quanto o ponto de chegada da ciência passaram a estar ancorados nas contingências imediatas do mundo material. Este processo de construção da noção

\footnotetext{
${ }^{1}$ Este trecho encontra-se em nota não publicada de Hooke, reproduzida em Middleton (1965: 145).
} 
moderna de ciência avança rapidamente na esteira de duas revoluções, uma política e a outra científica.

\section{NEWTON, REVOLUÇÃO E TECNOLOGIA}

O massivo sistema de filosofia natural construído por Newton ao final do século XVII constitui, sem dúvida, um dos monumentos-chave da cultura moderna. É difícil superestimar seu impacto e sua influência imediata; o impressionante edifício teórico da síntese newtoniana coroou quase um século de pesquisas mecânicas empiricamente orientadas, conferindo autoridade ao programa experimental. Mesmo assim, embora concebidos no seio da Revolução Científica e sob a influência da Royal Society, os Principia não estavam sequer próximos de ser um livro de divulgação. Além de sua formulação envolver um altíssimo grau de abstração (afastando-se da análise das questões empíricas imediatas, tão cara à Sociedade), o leitor que pretendesse compreender a obra de Newton deveria dispor de uma vasta bagagem conceitual e matemática - embora sua Opticks possuísse maior apelo junto ao público, com proposições menos rigorosas e formuladas de forma mais intuitiva. Se por um lado a obra de Newton representava uma revolução científica definitiva, por outro dificilmente poderia se tornar responsável pela aproximação entre o cientista e a sociedade, entre o cientista e os homens práticos responsáveis pelo progresso material.

Não obstante, foi precisamente neste contexto que a aproximação ocorreu, no contexto de absorção da genialidade de Newton e de reorientação política pósRevolução de 1688. As duas revoluções, ocorrendo quase simultaneamente, foram associadas ao início de uma nova era. Dentro do novo cenário de liberalismo político e religioso, a síntese newtoniana foi abraçada pelos vitoriosos como símbolo do poder da ciência, da investigação e da vontade humana. Jacob assim descreve esta transição crucial:

The cultural ascendancy of science in the late seventeenth century - from a body of knowledge once promoted by its select devotees in Florence, Paris, or London, to the cornerstone of progressive thought among the educated laity - occurred with extraordinary rapidity. We can date that transformation in the role of science in Western culture quite precisely from the 1680 s to the 1720 s. Within one generation the transformation was complete in northern and western Europe, and mechanically based science had left the hands of its first crusaders and visionaries and gone into the everyday language of journalists, learned societies, coffeehouse lectures, and church sermons. As a result, it transformed the way urban merchants, progressive aristocrats, and just simply literate gentlemen, and some gentlewomen, understood the physical world around them (Jacob, 1988: 105). 
O programa experimental, conduzido por homens livres em um contexto de discussão e diálogo civilizados, em busca de um conhecimento objetivo e demonstrável, possuía apelo imediato para os defensores da nova ordem política (Shapin \& Schaffer, 1985: 332-344). Mas apesar do ambiente cultural favorável, ainda era necessário trazer a ciência newtoniana para o domínio do cotidiano, transformá-la em algo palpável, útil. É claro que o próprio Newton não foi totalmente impermeável a questões de ordem prática, tendo dedicado, por exemplo, muitos esforços à solução do premente problema do cálculo da longitude no mar (Merton, 1984: 193-200). Mas foi a seus discípulos que coube a tarefa de estabelecer a conexão definitiva entre síntese newtoniana e tecnologia.

A preocupação com a aplicação prática dos princípios newtonianos compôs a agenda da Royal Society desde muito cedo. A Sociedade se preocupava cada vez mais em oferecer subsídios técnicos e científicos para o aprimoramento de ofícios, em linha com seus vínculos estreitos com as elites urbanas (Jacob, 1988: 92-93). Conforme afirma Larry Stewart:

Any assumption that the Society or its Fellows were uniformly antagonistic to trade or to commerce does not stand up to scrutiny. [...] Whether or not Boyle or Newton was interested in practical questions is no the issue here. More significant was the contact between the entrepreneur and the inventor, and between the entrepreneur and the natural philosopher. In this respect, the early Newtonians represented the adherence to a long tradition. Whatever might be assumed about the official attitude of the Royal Society, it is evident that there antedated its foundation a long standing tradition of practical interests among natural philosophers. [...] Rhetoric, at least, had established common ground for philosophers and merchants in the improvement of trade (Stewart, 1992: 168-169)

No início do século XVIII, os avanços técnicos até então alcançados já permitiam vislumbrar a possibilidade de aplicação prática dos princípios newtonianos. Os seguidores de Newton assumiram para si a tarefa de divulgar e popularizar as ideias do mestre, colocando-as ao alcance de indivíduos sem treinamento científico. Homens como John Teophilus Desaguliers e William Derham dedicaram-se a elaborar manuais simplificados da mecânica de Newton e, mais do que isto, a promover palestras e cursos em que suas ideias eram demonstradas de forma simples e ilustrativa. Estas palestras não se limitavam aos domínios da capital, adentrando também os núcleos urbanos das províncias. Toda uma geração de cientistas e técnicos da primeira metade do século XVIII encontrou nestas atividades de popularização da nova ciência seu ofício e seu sustento (Jacob, 1988: 130-144; Stewart, 1992, passim).

A divulgação promovida pelos newtonianos possuía apelo junto ao público devido a certo grau de teatralidade. A adoção dos cânones do programa experimental como forma de demonstração da validade da mecânica de Newton criava algo parecido com um ambiente de entretenimento, em que os experimentos pre- 
feridos eram aqueles de maior impacto dramático sobre a audiência leiga (Stewart, 1992: 118). Além disso, havia a sempre premente necessidade de associar os abstratos princípios científicos com a realidade imediata dos espectadores. Neste ponto, os newtonianos foram os responsáveis pela consolidação dos vínculos entre a nova ciência e os empreendedores, projetistas, homens de negócio e demais indivíduos que viam as recentes descobertas como potenciais fontes de recompensa material. Ao buscar ampliar suas audiências (e seus rendimentos), os newtonianos esforçaram-se por atender estas expectativas, afastando-se de demonstrações abstratas e privilegiando aplicações práticas imediatas:

Although abstruse metaphysics must prove impossible to resolve, true philosophy would emerge in the social world as that knowledge that made mines workable and engines more reliable (Stewart, 1992: 106).

Estabeleceu-se uma parceria, uma cooperação, até mesmo uma cumplicidade entre filósofos newtonianos e empreendedores. Nesta nova organização social, mercadores e artesãos haviam alcançado um posto que lhes garantia acesso privilegiado aos mais recentes avanços do conhecimento. Cientes da menor relevância de curiosidades intelectuais aristocratas nesta nova ordem, os popularizadores de Newton mobilizaram-se para atender às novas demandas do mercado. Na pauta do dia, novos e velhos problemas técnicos, entre eles um que nos é especialmente familiar:

Desaguliers [...] in 1719, advertised his Course of Experimental Philosophy to include an improvement on the Savery engine "of the greatest Use for draining Mines, supplying Towns with Water, and Gentlemens Houses..." [...] the difficulties of flooded mines ensured sufficient interest in the possibilities frequently claimed for natural philosophy (Stewart, 1992: 147).

\section{NEWCOMEN E A TECNOLOGIA CIENTÍFICA}

$\mathrm{Na}$ Inglaterra das primeiras décadas do século XVIII, os laços entre avanços científicos e solução de problemas práticos estavam sendo intensificados pela ação conjunta de dois fatores: o ambiente progressista e liberal instaurado após a Revolução de 1688 e a popularização da síntese newtoniana levada a cabo por seus seguidores. Durante este período, cresceu a confiança, tanto de leigos quanto de especialistas, quanto à possibilidade de aplicação dos princípios da nova ciência visando ao aprimoramento das condições materiais da humanidade. Auxiliados ainda pelas condições financeiras favoráveis, às vésperas do estouro da South Sea Bubble, despontaram inúmeros ambiciosos projetos mecânicos, alguns sóbrios, outros delirantes. Para além de seu derradeiro sucesso ou fracasso, estes projetos possuíam características em comum. Neles, entrevia-se um desejo de aplicação econômica das descobertas científicas - utilizar a nova ciência como investimento, como forma de 
auferir ganhos; além disso, nos grupos de trabalho formados para colocar em prática estas propostas, conviviam cientistas puros, empresários e investidores, técnicos, artesãos, fabricantes de instrumentos, uma vasta gama de indivíduos necessários para realizar a difícil transposição entre as ideias e a prática. Esta convivência e troca de experiências e informações configuram um momento-chave na conformação da simbiose definitiva entre ciência, tecnologia e progresso econômico.

Assim como na época de Galileu, o problema da drenagem das minas continuava apresentando desafios constantes a proprietários e técnicos encarregados. O carvão era a principal fonte de energia de uma economia inglesa em franca expansão, exercendo uma pressão constante sobre a capacidade produtiva das minas - pressão que se traduzia em explorações a maior profundidade. A solução encontrada à época para o problema encontra-se no ápice de uma linha de desenvolvimento que se inicia com as descobertas pioneiras de Torricelli e Guericke. Embora estas descobertas não possuíssem inicialmente grande utilidade prática, após meio século de pesquisas e experimentos sua transposição para a solução do problema da drenagem finalmente pôde ser realizada com sucesso.

A primeira aplicação bem-sucedida do princípio da pressão atmosférica na drenagem de minas deve-se a Thomas Savery, um engenheiro militar educado em matemática e filosofia natural, membro da Royal Society (Cardwell, 1972: 58-59; Wolf, 1962: 551). A máquina atmosférica de Savery realizava o trabalho de drenagem por meio de sucção induzida pela condensação de vapor. $O$ vapor é transmitido ao recipiente principal, exaurindo o ar. A subsequente condensação do vapor, exposto à temperatura ambiente, cria um vácuo que suga a água da mina em direção ao recipiente, por meio da ação da pressão atmosférica. Fecha-se então o contato dos dutos com a mina e abre-se outro contato por onde a água, após nova injeção de vapor, será exaurida do recipiente, liberando-o para nova etapa de condensação e sucção (Jones, 1969: 453-454).

Embora funcional, a máquina atmosférica de Savery era pouco eficiente: consumia muita energia (carvão para geração de vapor) e trabalhava com um limite de elevação insatisfatório em grande parte dos casos, devido à pressão sobre o recipiente principal. Desta forma, a disseminação de seu uso foi bastante restrita. Coube a Thomas Newcomen a idealização de uma nova máquina atmosférica economicamente viável que finalmente possibilitaria a exploração de minas de grande profundidade. A principal inovação de Newcomen foi substituir o recipiente onde se alternavam vapor e água, na máquina de Savery, por um sistema mais complexo onde um pistão, acoplado a um cilindro oco, conecta-se por meio de uma alavanca a uma bomba de água. Quando o cilindro é preenchido com vácuo, o pistão sobe e a outra extremidade da alavanca desce até a altura da água subterrânea. Em seguida o vapor é condensado no cilindro com um jato de água fria, fazendo com que o pistão desça, sob o efeito da pressão atmosférica, erguendo a alavanca e extraindo água do poço. O vapor condensado e o ar são extraídos do cilindro e o ciclo recomeça com nova injeção de vapor (Jones, 1969: 454-455).

$\mathrm{Na}$ primeira seção deste artigo transcrevi uma passagem em que Mokyr demonstrava certa surpresa ante o fato de que as descobertas de Torricelli e Guericke 
haviam chegado até Newcomen, muito embora este não fizesse parte do "mundo dos cosmopolitas cientistas acadêmicos". Entretanto, o mecanismo desta transmissão foi bastante direto, evidenciando o alto grau de integração então existente entre desenvolvimentos científicos e tecnológicos. Newcomen, um homem prático que presenciara a operação de algumas das máquinas de Savery instaladas nas minas de Cornwall, mantinha intenso contato com um membro da Royal Society, dentre todos certamente o mais versado em questões técnicas e experimentais. Refiro-me, é claro, a Robert Hooke. Durante os últimos anos do século XVII, Newcomen e Hooke trocaram correspondências cujo tema principal era a adaptação prática do princípio proposto por Denis Papin em 1690 para aplicação do vapor como força motriz sobre um pistão. Newcomen obteve sucesso em seu projeto logo após a morte de Hooke, em 1703, obtendo para sua invenção uma patente conjunta com Savery. Em pouco tempo, as máquinas de Newcomen se disseminaram por toda a Inglaterra, e logo pela Europa (Jones, 1969: 454-455; Usher, 1993: 451).

Assim, percebemos que, quando a solução para o problema da drenagem das minas finalmente surgiu, foi por obra do esforço conjunto de indivíduos igualmente interessados nos aspectos teóricos e práticos do conhecimento científico; indivíduos que se mantinham constantemente informados sobre os mais recentes desenvolvimentos da ciência pura, porém sempre preocupados em utilizá-los na solução de problemas concretos, imediatos. Mais do que isto, a solução surgiu em um momento em que a sociedade mostrava-se cada vez mais ansiosa por esta transposição bem-sucedida dos avanços científicos para os domínios da vida material. Como afirma Cardwell, "Francis Bacon would [...] have been delighted with Newcomen” (1972: 66). Após mais de meio século de árduas batalhas, o programa baconiano finalmente emergia triunfante e inconteste.

James Watt, o grande ícone da Revolução Industrial, é mais um exemplo contundente de como este novo estado de coisas já se encontrava profundamente arraigado ao longo do século XVIII, antes das grandes transformações na base técnica que marcaram a passagem para o século seguinte. Watt foi educado sob a influência da nova ciência. Seu avô era professor de matemática, profissão na qual instruiu o filho. $\mathrm{Na}$ casa em que Watt cresceu, havia um retrato de Newton pendurado em uma das paredes (Jones, 1969: 450). Sob a influência do trabalho do pai, que se especializara na confecção de instrumentos para navegação, Watt decidiu dedicar-se ele também ao ofício. Em busca de formação científica e técnica, Watt foi para a Universidade de Glasgow, onde teve oportunidade de desenvolver suas habilidades na fabricação de instrumentos, além de travar contato com várias figuras proeminentes da comunidade científica da época. Os vínculos assim consolidados exerceram influência decisiva sobre as pesquisas e inovações que levariam a suas versões compactas e aperfeiçoadas da máquina a vapor (Jones, 1969: 451-452).

Como afirma Cardwell, o treinamento acadêmico e a convivência com cientistas em Glasgow moldaram a perspectiva de Watt diante de problemas técnicos: sua abordagem era essencialmente científica, e não prática (1972: 85). Também sobre Watt se fizeram sentir os impactos da campanha de popularização dos newtonianos, pois quando criança seu pai o educara em matemática por meio do 
manual de S'Gravessande, traduzido do holandês para o inglês por Desaguliers (Robinson, 1970: 224). Watt era, de fato, um filho dos novos tempos. Educado cientificamente sob a massiva sombra de Newton, versado em questões técnicas e treinado na fabricação de instrumentos mecânicos, determinado a colocar a ciência a serviço do bem-estar material da humanidade. Mais ainda, Watt pertencia a um ambiente social que estimulava e congratulava os avanços perseguidos e eventualmente alcançados por homens como ele próprio; um ambiente em que filósofos, cientistas, artesão e indivíduos empreendedores trabalhavam juntos em torno de um propósito único, socialmente sancionado; um ambiente em que, nas palavras de Robinson (1970: 227), "he could hob-nob with the leading experimental scientists of the day as well as with the great entrepreneurs of the Industrial Revolution". Os resultados desta fértil interação mudaram irrevogavelmente as feições do mundo.

\section{CONCLUSÃO}

Nestes comentários finais, gostaria de recorrer às palavras de Margaret Jacob, ao refutar como historicamente ingênua a ideia de que a Revolução Industrial foi fruto do trabalho de pessoas simples e práticas, independentemente das contribuições da ciência:

The statement is historically false because it presumes a distinction between the 'scientist' and all others that simply did not exist in the late eighteenth century when industrialization began, first in England, then in Belgium and Switzerland. [...] In addition the falsity of the statement arises from the naïve assumption that somehow human beings are born to think 'mechanically', in the post-Scientific Revolution meaning of the term. In consequence 'the people of little or no education', who supposedly made the Industrial Revolution, are presumed to have understood mechanical principles of nature, to have thought about steam and water as mechanically controllable matter without having been in some manner educated to that assumption (Jacob, 1988: 179).

Relatively sophisticated mechanical knowledge had to be a part of one's mental world before such mechanical devices could be invented and, more to the point, exploited. Where that knowledge was widespread, and where capital, natural resources, and exploitable labor were also present, the results of that coincidence transformed both nature and society, creating in its wake the modern industrial world (Idem: 209).

Durante o século XVII e as primeiras décadas do século XVIII, o mundo ocidental testemunhou uma transformação profunda na apreciação do papel a ser desempenhado pela ciência nos desígnios maiores da humanidade. Esta transfor- 
mação partiu de dentro dos próprios círculos científicos, por obra de homens como Bacon e Galileu; porém foi transmitida ao corpo geral da sociedade quando a ciência e seus porta-vozes passaram a falar uma linguagem que aludia de forma mais direta aos problemas cotidianos enfrentados por todos, prometendo que a nova ciência, se propriamente conduzida, poderia oferecer soluções e mudar suas vidas. A história dos avanços registrados no campo da pneumática, culminando na inovação crucial da máquina a vapor, ilustra com muita riqueza esta transformação. Problemas técnicos estavam na raiz das experiências de Torricelli, e suas descobertas conduziram a uma série de desdobramentos e depurações que finalmente culminaram em uma inovação crucial, a energia a vapor. Neste processo, colaboraram indivíduos de todas as partes da Europa, alguns com vocações técnicas, outros com vocações filosóficas, outros apenas dotados de incansável curiosidade intelectual. Em sua interação e nos notáveis resultados alcançados, disseminaram um novo credo - o mecanicismo que transformou ciência e tecnologia em duas modalidades complementares e indissociáveis de compreensão da realidade.

\section{REFERÊNCIAS}

BENNETT, J. A. (1980-1981) "Robert Hooke as mechanic and natural philosopher", Notes and Records of the Royal Society, 35: 33-48.

CARDWELL, D. S. L. (1972) Turning points in Western technology, New York: Science History Publications.

HALL, Rupert (1967) "Scientific method and the progress of techniques". In: The Cambridge economic history of Europe, London: Cambridge University Press, vol. IV: 96-154.

JACOB, Margaret C. (1988) The cultural meaning of the scientific revolution. New York: Alfred E. Knopf.

JONES, R. V. (1970) “The Wilkins lecture: the 'plain story' of James Watt”. Proceedings of the Royal Society of London, Series A, Mathematical and Physical Sciences, vol. 316, $\mathrm{n}^{\circ}$ 1527: 449-471.

MERTON, Robert K. (1984) Ciencia, tecnología y sociedad en la Inglaterra del siglo XVII, Madrid: Alianza Editorial.

MIDDLETON, W. E. Knowles (1965) "A footnote to the history of the barometer". Notes and Records of the Royal Society of London, XX: 145-51.

MOKYR, Joel (1990) The lever of riches: technological creativity and economic progress, New York: Oxford University Press.

MOKYR, Joel (1993) “Editor's introduction”. In: The British Industrial Revolution: an economic perspective, Boulder: Westview Press.

MOKYR, Joel (2005) "The Intellectual origins of modern economic growth", Journal of Economic History, 65(2): 285-351.

ROBINSON, Eric (1970) "James Watt, engineer and man of science". Notes and Records of the Royal Society of London, 24(2): 221-232.

ROSENBERG, Nathan (1982) Inside the black box: technology and economics, Cambridge: Cambridge University Press.

SHAPIN, Steven \& SCHAFFER, Simon (1985) Leviathan and the air-pump: Hobbes, Boyle and the experimental life, Princeton: Princeton University Press.

STEWART, Larry (1992) The rise of public science: rhetoric, technology, and natural philosophy in Newtonian Britain, 1660-1750, Cambridge: Cambridge University Pres.

USHER, Abbott Payson (1993) Uma história das invenções mecânicas, São Paulo: Papirus.

WOLF, A. (1962) A history of science, technology and philosophy in the 16th and 17th centuries, London: George Allen \& Unwin Ltd., 2 vols. 